\title{
Neural Stem Cells and Ischemic Brain
}

\author{
Zhenggang Zhang, ${ }^{a}$ Michael Chopp ${ }^{\mathrm{a}, \mathrm{b}}$ \\ ${ }^{a}$ Henry Ford Hospital, Michigan, United States \\ bDepartment of Physics, Oakland University, Rochester, Michigan, United States
}

Stroke activates neural stem cells in the ventricular-subventricular zone (V/SVZ) of the lateral ventricle, which increases neuroblasts and oligodendrocyte progenitor cells (OPCs). Within the ischemic brain, neural stem cells, neuroblasts and OPCs appear to actively communicate with cerebral endothelial cells and other brain parenchymal cells to mediate ischemic brain repair; however, stroke-induced neurogenesis unlikely plays any significant roles in neuronal replacement. In this mini-review, we will discuss recent findings how intercellular communications between stroke-induced neurogenesis and oligodendrogenesis and brain parenchymal cells could potentially facilitate brain repair processes.

keywords Adult neurogenesis; Stroke; Brain repair; Stem cells

\author{
Correspondence: Zhenggang Zhang \\ Henry Ford Hospital, Michigan, United \\ States \\ Tel: +1-313-916-5456 \\ Fax: +1-313-916-1318 \\ E-mail:zhazh@neuro.hfh.edul
}

Received: March 25, 2016

Revised: May 13, 2016

Accepted: May 18, 2016

\begin{abstract}
NIH, R01 NS 088656 (MC) and R01 NS079612 (ZG). The content is solely the responsibility of the authors and does not necessarily represent the official views of the National Institutes of Health.

The authors have no financial conflicts of

interest.
\end{abstract}

\section{Introduction}

In the adult mammalian brain, there are at least two neurogenic regions: the ventricular-subventricular zone (V/SVZ) of the lateral ventricle and the subgranular zone of the dentate gyrus. ${ }^{1-5}$ Neural stem cells within these two neurogenic niches generate new neurons throughout the life of the animal. ${ }^{6}$ Within the adult rodent $\mathrm{V} / \mathrm{SVZ}$, the largest germinal niche, quiescent and activated neural stem cells coexist. ${ }^{7-9}$ Activated neural stem cells divide to expand intermediate progenitor cells. ${ }^{7-9}$ Neuroblasts generated by differentiation of the neural progenitor cells travel via the rostral migratory stream to the olfactory bulb, where they differentiate into granule and periglomerular neurons. ${ }^{1}$ Adult neural stem cells in the V/SVZ also generate oligodendrocyte progenitor cells (OPCs) that disperse to the gray and white matter. ${ }^{10-13}$ Focal cerebral ischemia in the adult rodent increases neurogenesis mainly in the $V / S V Z$, and augmented neuroblasts migrate from the V/SVZ to the ischemic boundary. ${ }^{2,14-16}$ Stroke-induced neuro- genesis has also been demonstrated in the adult human brain..$^{17-19}$ In addition, preclinical studies show that stroke also increases OPCs in the V/SVZ and these OPCs disperse to the peri-infarct region of the corpus callosum to differentiate into myelinating oligodendrocytes..$^{20-24}$ These findings, in particular neurogenesis, have led to a hope for re-establishment of damaged neuronal circuitry mediated by integration of stroke-induced new neurons. ${ }^{2,14-16}$ However, subsequent experimental studies show that only a fraction of neuroblasts in the peri-infarct regions become mature neurons with phenotypes of interneurons, and these new neurons eventually die. ${ }^{25-27}$ On the other hand, stroke continuously induces neuroblasts which migrate to peri-infarct regions for at least one year, ${ }_{1}^{28}$ and ablation of neuroblasts after stroke reduces ischemic brain repair and exacerbates functional recover.. ${ }^{29}$ Together, these data suggest that stroke-increased neurogenesis is involved in the brain repair process via mechanisms that are independent of replacement of dead neurons to re-wire neuronal circuitry. In this review, we will detail the effect of 
stroke-induced neuroblasts and OPCs on brain parenchymal cells in ischemic brain with a focus on the brain repair processes.

\section{Coupling of neural stem cells, cerebrospinal fluid (CSF), and cerebral endothelial cells}

In the adult V/SVZ neurogenic niche, cerebral blood vessels form a distinctive planar vascular plexus, and these blood vessels differ from the vascular structure in other brain regions, and permit small molecules to pass the blood brain barrier and to enter the SVZ. ${ }^{11,30,31}$ Adult neural stem cells bridge the ventricle and the rich plexus of blood vessels in the SVZ via the apical single cilium of neural stem cells anchored on the ventricular surface and make direct contact with the CSF, whereas long basilar processes of neural stem cells eventually reach and directly contact blood vessels of this plexus in the SVZ. ${ }^{10,32}$ Given this unique architecture, neural stem cells are well positioned to sample secreted factors in the CSF and to communicate with cerebral endothelial cells. Within the V/SVZ neurogenic niche, direct contact between neural stem cells and endothelial cells is essential to maintain adult neural stem quiescence. ${ }^{33}$ Endothelial cells suppress active proliferation of neural stem cells via endothelial ephrinB2 and Jagged 1 to interact with neural stem cell Notch and Eph, respectively. ${ }^{33}$ Cerebral vasculature also releases factors, such as integrin $\alpha 6$ and $\beta 1$, to regulate neural stem and progenitor cell biologic function. ${ }^{30,31}$ Actively proliferating intermediate neural progenitor cells in the SVZ are localized to blood vessels." These data indicate coupling of adult neural stem cells with cerebral endothelial cells. ${ }^{34}$ Stroke robustly increases neural stem cells and new blood vessels within the V/SVZ niche. ${ }^{32}$ Increased neural stem cell contact with the CSF and augmented blood vessels just beneath the ependymal layer suggest that quiescent adult neural stem cells in the V/SVZ niche may be recruited to an active pool to increase the neurogenic process in response to ischemic insult. ${ }^{32}$ In vitro studies have demonstrated that primary cerebral endothelial cells isolated from ischemic brain promote proliferation and neuronal differentiation of non-ischemic SVZ neural progenitor cells, and neural progenitor cells isolated from ischemic SVZ enhance in vitro angiogenesis of non-ischemic cerebral endothelial cells. ${ }^{35}$ The vascular endothelial growth factor/vascular endothelial growth factor receptor 2 signaling pathway mediates coupling of neural progenitor cells and cerebral endothelial cells. ${ }^{35}$ In addition to the V/SVZ niche, increased neuroblasts induced by stroke in the V/SVZ migrate along cerebral blood vessels to peri-infarct regions where angiogenesis occurs. ${ }^{36-40}$ Soluble molecules and their receptors mediate vascular-coupled neuroblast migration in ischemic brain, such as angiopoietin-1
(Ang1)/Tie2, stromal-derived factor-1 $\alpha /$ chemokine receptor 4 (CXCR4), and among others. ${ }^{35-40}$ Although new interneurons differentiated from neuroblasts in the peri-infarct regions eventually die, ablation of neuroblasts after stroke has an adverse effect on ischemic brain repair and worsens functional recovery. ${ }^{29}$ These data suggest that increased neuroblasts are involved in brain repair processes after stroke.

Emerging data indicate that exosomes can also mediate the coupling of neural stem cells, CSF, and cerebral endothelial cells within the V/SVZ niche (Figure 1). Exosomes are endosome-derived nanovesicles and carry proteins, lipids, and genetic materials. ${ }^{41,42}$ Exosomes play essential roles in intercellular communication by transferring their cargo between source and target cells under physiological and pathophysiological conditions. ${ }^{41,42}$ There is evidence that exosomes in the CSF of rats and humans promote neural stem cell proliferation, possibly via delivering exosomal cargo protein and miRNA components of the insulin-like growth factor signaling pathway to neural stem cells. ${ }^{43}$ Exosomes derived from ischemic cerebral endothelial cells facilitate proliferation and neuronal differentiation of adult neural progenitor cells, whereas exosomes harvested from ischemic neural progenitor cells increase in vitro angiogenesis. ${ }^{44}$ These data suggest that exosomes mediate interactions between neural stem cells and cerebral endothelial cells under ischemic conditions. Thus, exosomes released by stroke-triggered neural stem cells and neuroblasts could communicate with brain parenchymal cells to amplify ischemic brain repair.

\section{The effect of neural stem cells/ neuroblasts on axonal remodeling}

Neuronal circuitry regulates adult neural stem cell quiescence in the subgranular zone. ${ }^{45}$ Axons from serotonergic (5HT) neurons in the raphe nuclei directly contact adult neural stem cells in the V/SVZ niche and regulate neural stem cell proliferation through the interaction of $5 \mathrm{HT} 2$ and $5 \mathrm{HT} 2 \mathrm{C}$ receptor in neural stem cells. ${ }^{46}$ However, it is unknown whether neural stem cells and neuroblasts have an impact on axons and neuronal circuitry. During cortical development, SVZ intermediate progenitor cells facilitate intracortical progression of thalamocortical axons through the stromal-derived factor- $1 \alpha / C X C R 4$ signaling pathway. ${ }^{47}$ Adult SVZ neural progenitor cells express stromal-derived factor- $1 \alpha$ and CXCR4. ${ }^{48}$ In addition to the chemokine signals, adult neural stem cells in the V/SVZ release exosomes. ${ }^{44,49}$ Cultured axons of cortical neurons can take up exosomes and miRNAs from internalized exosome cargo which thereby regulate axonal growth. ${ }^{50}$ Stroke induces limited axonal sprouting in the peri-infarct region. ${ }^{21,22,51,52}$ Extra-cellular factors and intrinsic sig- 

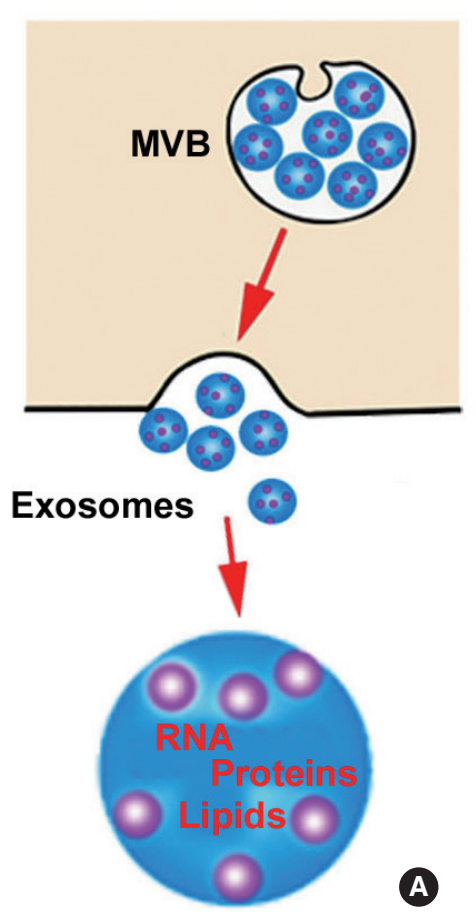

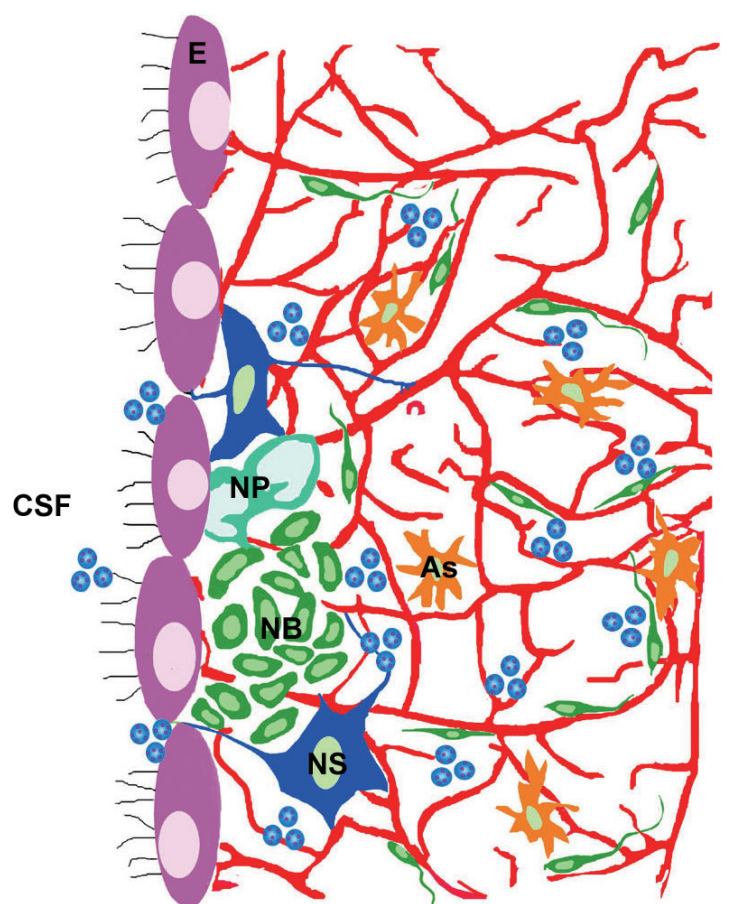

B

Figure 1. Diagram outlining inter-cellular communications of exosomes within the neurogenic niche. Panel A shows that the multivesicular body (MVB) fuses with the cell membrane (arrow) to release exosomes into the extracellular milieu. Exosomes contain genetic materials, proteins and lipids. Panel B shows the presence of exosomes in cerebrospinal fluid (CSF) and the ventricular-subventricular zone (V/SVZ) neurogenic niche. E, ependymal cells; NS, neural stem cells; NP, neural progenitor cells; NB, neuroblasts; As, astrocytes.

nals of axons mediate axonal regeneration after axonal injury..$^{53}$ Thus, it will be important to determine whether the stromal-derived factor- $1 \alpha / C X C R 4$ signaling pathway and exosomes released by neural stem cells in the V/SVZ and neuroblasts in periinfarct regions regulate axonal remodeling in ischemic brain.

\section{The effect of neural stem cells on oligodendrogenesis}

In the embryonic brain, OPCs arise from the VZ and migrate along vasculature throughout the brain. ${ }^{54} \mathrm{Wnt}$ and CXCR4 signaling mediate OPC-endothelial interactions to coordinate OPC migration and differentiation. ${ }^{54}$ Adult neural stem cells in the V/ SVZ also generate OPCs that comprise $\sim 5 \%$ of the total cell number in the adult rodent brain and distribute throughout the grey and white matter. ${ }^{55-57}$ OPCs are the most actively proliferating cells in the adult brain and differentiate into mature oligodendrocytes to myelinate previously unmyelinated axons. ${ }^{58}$ Stroke acutely induces mature oligodendrocyte damage, leading to loss of myelin, ${ }^{59}$ which is associated with loss of axons. ${ }^{60,61}$ New myelinating oligodendrocytes are generated by differentiation of OPCs. In contrast to neuroblasts, OPCs in ischemic brain survive and differentiate into myelinating oligodendrocytes. ${ }^{20-24}$
As demonstrated by a cell fate mapping strategy, stroke increases neural stem cell-derived OPCs in the V/SVZ and promotes these OPCs to differentiate into myelin forming oligodendrocytes in peri-infarct white matter. ${ }^{20-24}$ Thus, adult neural stem cells contribute to oligodendrogenesis after stroke. In addition to myelination, OPCs act as a surveillance network to detect brain injury and couple with cerebral endothelial cells. ${ }^{62,63}$ Recent studies suggest that OPCs interact with microglia via OPC-released exosomes to regulate brain immune function. ${ }^{64}$ Furthermore, OPCexosomes promote neuronal survival under conditions of cell stress. ${ }^{65}$ It remains to be investigated whether and how OPCs generated by adult neural stem cells are involved in brain repair processes other than oligodendrogenesis after stroke.

Astrocytes and microglia also interact with SVZ neural stem cells and neuroblasts, which has recently been reviewed. ${ }^{66,67}$

\section{Conclusions}

Stroke activates adult neural stem cell function in the V/SVZ, leading to neurogenesis and oligodendrogenesis in the ischemic brain. Although new neurons do not replace damaged neurons, stroke-increased neural stem cells and neuroblasts seem to participate in brain repair processes by communicating with cere- 
bral vasculature and other brain parenchymal cells. OPCs generated by V/SVZ neural stem cells are also involved in ischemic brain repair processes. It will be important to investigate how neural stem cells, neuroblasts and OPCs communicate among themselves and with other brain cells, and in turn, mediate ischemic brain repair processes. These preclinical studies will potentially provide new strategies for enhancement of stroke-induced neurogenesis and oligodendrogenesis, consequently leading to improvement of neurological function after stroke. However, it remains to be demonstrated whether these inter-cellular communications between stroke-induced neurogenesis and parenchymal cells are involved in brain repair of patients with stroke.

\section{References}

1. Alvarez-Buylla $A$, Herrera DG, Wichterle $H$. The subventricular zone: source of neuronal precursors for brain repair. Prog Brain Res 2000;127:1-11.

2. Arvidsson A, Collin T, Kirik D, Kokaia Z, Lindvall 0. Neuronal replacement from endogenous precursors in the adult brain after stroke. Nat Med 2002;8:963-970.

3. Zhang R, Zhang Z, Wang L, Wang Y, Gousev A, Zhang L, et al. Activated neural stem cells contribute to stroke-induced neurogenesis and neuroblast migration toward the infarct boundary in adult rats. J Cereb Blood Flow Metab 2004;24:441-448.

4. Jin K, Sun Y, Xie L, Peel A, Mao XO, Batteur S, et al. Directed migration of neuronal precursors into the ischemic cerebral cortex and striatum. Mol Cell Neurosci 2003;24:171-189.

5. Parent JM. Injury-induced neurogenesis in the adult mammalian brain. Neuroscientist 2003;9:261-272.

6. Ihrie RA, Alvarez-Buylla A. Lake-front property: a unique germinal niche by the lateral ventricles of the adult brain. Neuron $2011 ; 70: 674-686$.

7. Furutachi S, Miya H, Watanabe T, Kawai H, Yamasaki N, Harada $Y$, et al. Slowly dividing neural progenitors are an embryonic origin of adult neural stem cells. Nat Neurosci 2015;18:657665.

8. Codega P, Silva-Vargas V, Paul A, Maldonado-Soto AR, Deleo

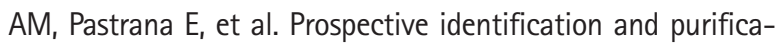
tion of quiescent adult neural stem cells from their in vivo niche. Neuron 2014;82:545-559.

9. Calzolari F, Michel J, Baumgart EV, Theis F, Götz M, Ninkovic J, et al. Fast clonal expansion and limited neural stem cell selfrenewal in the adult subependymal zone. Nat Neurosci 2015; 18:490-492.

10. Mirzadeh Z, Merkle FT, Soriano-Navarro M, Garcia-Verdugo JM, Alvarez-Buylla A. Neural stem cells confer unique pinwheel architecture to the ventricular surface in neurogenic re- gions of the adult brain. Cell Stem Cell 2008;3:265-278.

11. Silva-Vargas V, Crouch EE, Doetsch F. Adult neural stem cells and their niche: a dynamic duo during homeostasis, regeneration, and aging. Curr Opin Neurobiol 2013;23:935-942.

12. Miller FD, Gauthier-Fisher A. Home at last: neural stem cell niches defined. Cell Stem Cell 2009;4:507-510.

13. Kokovay E, Shen $Q$, Temple S. The incredible elastic brain: how neural stem cells expand our minds. Neuron 2008;60:420-429.

14. Zhang RL, Zhang ZG, Zhang L, Chopp M. Proliferation and differentiation of progenitor cells in the cortex and the subventricular zone in the adult rat after focal cerebral ischemia. Neuroscience 2001;105:33-41.

15. Parent JM, Vexler ZS, Gong C, Derugin N, Ferriero DM. Rat forebrain neurogenesis and striatal neuron replacement after focal stroke. Ann Neurol 2002;52:802-813.

16. Jin K, Minami M, Lan JQ, Mao XO, Batteur S, Simon RP, et al. Neurogenesis in dentate subgranular zone and rostral subventricular zone after focal cerebral ischemia in the rat. Proc Natl Acad Sci U S A 2001;98:4710-4715.

17. Jin $K$, Wang $X$, Xie L, Mao XO, Zhu W, Wang Y, et al. Evidence for stroke-induced neurogenesis in the human brain. Proc Natl Acad Sci U S A 2006;103:13198-13202.

18. Macas J, Nern C, Plate KH, Momma S. Increased generation of neuronal progenitors after ischemic injury in the aged adult human forebrain. J Neurosci 2006;26:13114-13119.

19. Minger SL, Ekonomou A, Carta EM, Chinoy A, Perry RH, Ballard CG. Endogenous neurogenesis in the human brain following cerebral infarction. Regen Med 2007;2:69-74.

20. Rafalski VA, Ho PP, Brett JO, Ucar D, Dugas JC, Pollina EA, et al. Expansion of oligodendrocyte progenitor cells following SIRT1 inactivation in the adult brain. Nat Cell Biol 2013;15:614-624.

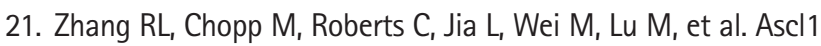
lineage cells contribute to ischemia-induced neurogenesis and oligodendrogenesis. J Cereb Blood Flow Metab 2011;31:614625.

22. Zhang RL, Chopp $M$, Roberts $C$, Wei $M$, Wang $X_{1}$ Liu $X_{1}$ et al. Sildenafil enhances neurogenesis and oligodendrogenesis in ischemic brain of middle-aged mouse. PLoS One 2012;7:e 48141.

23. Li L, Harms KM, Ventura PB, Lagace DC, Eisch AJ, Cunningham LA. Focal cerebral ischemia induces a multilineage cytogenic response from adult subventricular zone that is predominantly gliogenic. Glia 2010;58:1610-1619.

24. Zhang L, Chopp M, Zhang RL, Wang L, Zhang J, Wang Y, et al. Erythropoietin amplifies stroke-induced oligodendrogenesis in the rat. PLoS One 2010;5:e11016.

25. Liu F, You Y, Li X, Ma T, Nie Y, Wei B, et al. Brain injury does not alter the intrinsic differentiation potential of adult neuroblasts. 
J Neurosci 2009;29:5075-5087.

26. Bonfanti L. Adult neurogenesis 50 years later: limits and opportunities in mammals. Front Neurosci 2016;10:44.

27. Obernier K, Tong CK, Alvarez-Buylla A. Restricted nature of adult neural stem cells: re-evaluation of their potential for brain repair. Front Neurosci 2014;8:162.

28. Kazanis I, Gorenkova N, Zhao JW, Franklin RJ, Modo M, Ffrench-Constant $\mathrm{C}$. The late response of rat subependymal zone stem and progenitor cells to stroke is restricted to directly affected areas of their niche. Exp Neurol 2013;248:387-397.

29. Sun F, Wang $X_{1}$ Mao $X_{1}$ Xie $L$, Jin K. Ablation of neurogenesis attenuates recovery of motor function after focal cerebral ischemia in middle-aged mice. PLoS One 2012;7:e46326.

30. Shen O, Wang Y, Kokovay E, Lin G, Chuang SM, Goderie SK, et al. Adult SVZ stem cells lie in a vascular niche: a quantitative analysis of niche cell-cell interactions. Cell Stem Cell 2008;3: 289-300.

31. Tavazoie M, Van der Veken L, Silva-Vargas V, Louissaint M, Colonna $L$, Zaidi B, et al. A specialized vascular niche for adult neural stem cells. Cell Stem Cell 2008;3:279-288.

32. Zhang RL, Chopp $M$, Roberts $C$, Liu $X$, Wei M, Nejad-Davarani $S P$, et al. Stroke increases neural stem cells and angiogenesis in the neurogenic niche of the adult mouse. PLoS One 2014;9: e113972.

33. Ottone C, Krusche B, Whitby A, Clements M, Quadrato G, Pitulescu $M E$, et al. Direct cell-cell contact with the vascular niche maintains quiescent neural stem cells. Nat Cell Biol 2014;16:1045-1056.

34. Zhang ZG, Chopp M. Neurorestorative therapies for stroke: underlying mechanisms and translation to the clinic. Lancet Neurol 2009;8:491-500.

35. Teng $H$, Zhang ZG, Wang $L$, Zhang RL, Zhang $L$, Morris D, et al. Coupling of angiogenesis and neurogenesis in cultured endothelial cells and neural progenitor cells after stroke. J Cereb Blood Flow Metab 2008;28:764-771.

36. Tran PB, Ren D, Veldhouse TJ, Miller RJ. Chemokine receptors are expressed widely by embryonic and adult neural progenitor cells. J Neurosci Res 2004;76:20-34.

37. Robin AM, Zhang ZG, Wang L, Zhang RL, Katakowski M, Zhang $L$, et al. Stromal cell-derived factor 1alpha mediates neural progenitor cell motility after focal cerebral ischemia. J Cereb Blood Flow Metab 2006;26:125-134.

38. Zhang RL, Chopp M, Gregg SR, Toh Y, Roberts C, Letourneau Y, et al. Patterns and dynamics of subventricular zone neuroblast migration in the ischemic striatum of the adult mouse. J Cereb Blood Flow Metab 2009;29:1240-1250.

39. Zhang RL, LeTourneau Y, Gregg SR, Wang Y, Toh Y, Robin AM, et al. Neuroblast division during migration toward the isch- emic striatum: a study of dynamic migratory and proliferative characteristics of neuroblasts from the subventricular zone. $J$ Neurosci 2007;27:3157-3162.

40. Ohab JJ, Fleming S, Blesch A, Carmichael ST. A neurovascular niche for neurogenesis after stroke. J Neurosci 2006;26:1300713016.

41. Lai CP, Breakefield XO. Role of exosomes/microvesicles in the nervous system and use in emerging therapies. Front Physiol 2012;3:228.

42. György B, Hung ME, Breakefield XO, Leonard JN. Therapeutic applications of extracellular vesicles: clinical promise and open questions. Annu Rev Pharmacol Toxicol 2015;55:439-464.

43. Feliciano DM, Zhang S, Nasrallah CM, Lisgo SN, Bordey A. Embryonic cerebrospinal fluid nanovesicles carry evolutionarily conserved molecules and promote neural stem cell amplification. PLoS One 2014;9:e88810.

44. Pan W, Zhang X, Liu X, Li C, Hu J, Chopp M, et al. Exosomes derived from ischemic cerebral endothelial cells and neural progenitor cells enhance neurogenesis and angiogenesis. Stroke 2016;47(Suppl 1):AWMP39 (abstract).

45. Song J, Zhong C, Bonaguidi MA, Sun GJ, Hsu D, Gu Y, et al. Neuronal circuitry mechanism regulating adult quiescent neural stem-cell fate decision. Nature 2012;489:150-154.

46. Tong CK, Chen J, Cebrián-Silla A, Mirzadeh Z, Obernier K, Guinto $C D$, et al. Axonal control of the adult neural stem cell niche. Cell Stem Cell 2014;14:500-511.

47. Abe P, Molnár Z, Tzeng YS, Lai DM, Arnold SJ, Stumm R. Intermediate progenitors facilitate intracortical progression of thalamocortical axons and interneurons through CXCL12 chemokine signaling. J Neurosci 2015;35:13053-13063.

48. Liu XS, Chopp M, Santra M, Hozeska-Solgot A, Zhang RL,

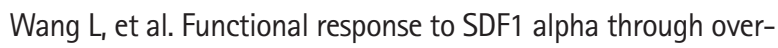
expression of CXCR4 on adult subventricular zone progenitor cells. Brain Res 2008;1226:18-26.

49. Cossetti C, Iraci N, Mercer TR, Leonardi T, Alpi E, Drago D, et al. Extracellular vesicles from neural stem cells transfer IFN- $\gamma$ via Ifngr1 to activate Stat1 signaling in target cells. Mol Cell 2014; 56:193-204.

50. Zhang Y, Chopp M, Liu XS, Katakowski M, Wang X, Tian X, et al. Exosomes derived from mesenchymal stromal cells promote axonal growth of cortical neurons. Mol Neurobiol 2016 Mar 19 [Epub ahead of print].

51. Ueno Y, Chopp M, Zhang L, Buller B, Liu Z, Lehman NL, et al. Axonal outgrowth and dendritic plasticity in the cortical periinfarct area after experimental stroke. Stroke 2012;43:22212228.

52. Gregersen $R$, Christensen $T$, Lehrmann $E$, Diemer NH, Finsen B. Focal cerebral ischemia induces increased myelin basic protein 
and growth-associated protein-43 gene transcription in periinfarct areas in the rat brain. Exp Brain Res 2001;138:384-392.

53. He $Z_{1}$ Jin $Y$. Intrinsic control of axon regeneration. Neuron 2016;90:437-451.

54. Tsai HH, Niu J, Munji R, Davalos D, Chang J, Zhang H, et al. Oligodendrocyte precursors migrate along vasculature in the developing nervous system. Science 2016;351:379-384.

55. Santra M, Chopp M, Zhang ZG, Lu M, Santra S, Nalani A, et al. Thymosin $\beta 4$ mediates oligodendrocyte differentiation by upregulating p38 MAPK. Glia 2012;60:1826-1838.

56. Franklin RJ, Ffrench-Constant C. Remyelination in the CNS: from biology to therapy. Nat Rev Neurosci 2008;9:839-855.

57. Menn B, Garcia-Verdugo JM, Yaschine C, Gonzalez-Perez O, Rowitch D, Alvarez-Buylla A. Origin of oligodendrocytes in the subventricular zone of the adult brain. J Neurosci 2006;26: 7907-7918.

58. McTigue DM, Tripathi RB. The life, death, and replacement of oligodendrocytes in the adult CNS. J Neurochem 2008;107:119.

59. Petito CK. Transformation of postischemic perineuronal glial cells. I. Electron microscopic studies. J Cereb Blood Flow Metab 1986;6:616-624.

60. Pantoni L, Garcia JH, Gutierrez JA. Cerebral white matter is highly vulnerable to ischemia. Stroke 1996;27:1641-1646; discussion 1647.

61. Dewar D, Underhill SM, Goldberg MP. Oligodendrocytes and ischemic brain injury. J Cereb Blood Flow Metab 2003;23:263274.

62. Hughes EG, Kang SH, Fukaya M, Bergles DE. Oligodendrocyte progenitors balance growth with self-repulsion to achieve homeostasis in the adult brain. Nat Neurosci 2013;16:668-676.

63. Miyamoto N, Pham LD, Seo JH, Kim KW, Lo EH, Arai K. Crosstalk between cerebral endothelium and oligodendrocyte. Cell Mol Life Sci 2014;71:1055-1066.

64. Fitzner D, Schnaars M, van Rossum D, Krishnamoorthy G, Dibaj P, Bakhti $M$, et al. Selective transfer of exosomes from oligodendrocytes to microglia by macropinocytosis. J Cell Sci 2011; 124:447-458.

65. Frühbeis C, Fröhlich D, Kuo WP, Amphornrat J, Thilemann S, Saab AS, et al. Neurotransmitter-triggered transfer of exosomes mediates oligodendrocyte-neuron communication. PLoS Biol 2013;11:e1001604.

66. Zhang ZG, Chopp M. Exosomes in stroke pathogenesis and therapy. J Clin Invest 2016;126:1190-1197.

67. Liu Z, Chopp M. Astrocytes, therapeutic targets for neuroprotection and neurorestoration in ischemic stroke. Prog Neurobiol 2015;pii:S0301-0082(15)30001-0. 